\title{
O ENSINO DE HISTÓRIA, CULTURA AFRICANA E AFRO-BRASILEIRA NO CURRÍCULO DO ESTADO DE SÃO PAULO
}

\author{
THE TEACHING OF HISTORY, AFRICAN AND AFRO-BRAZILIAN CULTURE \\ IN THE CURRICULUM OF THE STATE OF SÃO PAULO
}

Marley de Fátima Morais Borges ${ }^{1}$ Jonas Rafael dos Santos ${ }^{2}$

\section{Resumo}

Este artigo tem como objetivo analisar a Lei 10.639/03 e como estão inseridos os conteúdos determinados pelas "Diretrizes Curriculares Nacionais para Educação das Relações Étnico-raciais e para o Ensino de História e Cultura Afro-Brasileira e Africana" (BRASIL, 2004) nos currículos do Estado de São Paulo, em Ciências Humanas: História, Filosofia, Sociologia e Geografia, também Língua Portuguesa e Arte na área de Linguagens Códigos e suas tecnologias. A metodologia tem como referência a abordagem qualitativa de pesquisa em educação. E os referenciais teóricos utilizados têm como base estudos culturais que avançam na reescrita da história afro-brasileira de valorização da cultura africana de estudiosos como: Martha Abreu, Stuart Hall, Valter Silvério, Anderson Oliva, Kabengele Munanga, Tadeu Silva, Maria Candau entre outros. Através da análise documental foi possivel observar que o currículo do Estado de SP, sendo referenciado por competências é também espaço de cultura e possibilita aos professores e alunos se apropriarem de conhecimentos sobre: África e as questões étnico-raciais. Todavia, a investigação mostrou também os entraves que dificultam a efetivação da Lei 10.639/03 no lócus escolar.

Palavras-chave: Educação. Currículo. Questões-Étnico-racial. Lei $\mathrm{N}^{\circ}$ $10.639 / 2003$.

\begin{abstract}
This article aims to analyze Law 10.639 / 03 and how the content of the "National Curricular Guidelines for Ethnic-Racial Relations Education and for Teaching Afro-Brazilian and African History and Culture" (BRASIL, 2004) is Curriculum of the State of São Paulo, in Human Sciences: History, Philosophy, Sociology and Geography, also Portuguese Language and Art in the area of Codes Languages and their technologies. The methodology is based on the

\footnotetext{
${ }_{1}^{1}$ Mestra em Planejamento e Análise de Políticas Públicas, (Políticas públicas educacionais, Unesp/Franca).E-mail: marleyfmborges@yahoo.com.br

${ }^{2} \mathrm{O}$ autor é doutor em História pela UNESP/Franca e Professor do programa de Pós-graduação em Planejamento e Análise de Politicas Públicas, UNESP/Franca. E-mail: jrafsantos@yahoo.com.br
} 
qualitative approach of research in education. And the theoretical references used are based on cultural studies, which advance in the rewriting of AfroBrazilian history of appreciation of African culture, by scholars such as: Martha Abreu, Stuart Hall, Valter Silvério, Anderson Oliva, Kabengele Munanga, Tadeu Silva, Maria Candau among others. Through the documentary analysis it was possible to observe that the State of São Paulo curriculum, being referenced by competences, is also a space of culture and enables teachers and students to appropriate knowledge about: Africa and ethnic-racial issues. However, the research also showed the obstacles that impede the implementation of Law 10.639 / 03 in the school locus.

Key-words: Education. Curriculum. Ethnic-racial questions. Law $N^{\circ} .10 .639$ / 2003.

\section{Introdução}

O presente artigo traz uma discussão sobre a formulação e implementação do currículo em um jogo de força e poder, campo de luta este em que o currículo é sempre um processo inacabado, composto de escolhas, visões, interpretações, concepções de alguém ou de um grupo de sujeitos que, em determinado espaço social e/ou cultural em tempos históricos diferentes, detém o poder de determinar prioridades de conteúdos e metodologias curriculares. Nesta perspectiva, para Silva (1996)

O currículo é um dos locais privilegiados onde se entrecruzam saber e poder, representação e domínio, discurso e regulação. É também no currículo que se condensam relações de poder que são cruciais para o processo de formação de subjetividades sociais. Em suma, currículo, poder e identidades sociais estão mutuamente implicados. O currículo corporifica relações sociais. (SILVA, 1996, p. 23).

Portanto, os conteúdos selecionados, que podem ser eles: conceituais, procedimentais ou atitudinais, ao serem implementados em uma unidade escolar, sofrem transformações, adequações de acordo com a comunidade em que a instituição está inserida, há, ainda, a interferência da relação professor/aluno no processo de ensinar e aprender que dialoga com a formação dos profissionais da educação que ali trabalham. Considerando a importância destes fatores para compreensão da prática da Lei 10.639/03, 
foram analisados os currículos de História, Geografia, Filosofia, Sociologia, Arte e Língua Portuguesa, do estado de SP, como estão inseridos nestes documentos os conteúdos determinados pelas "Diretrizes Curriculares Nacionais para Educação das Relações Étnico-raciais e para o Ensino de História e Cultura Afro-Brasileira e Africana”. (BRASIL, 2004).

\section{A educação brasileira da constituição de 1988 a lei $n^{\circ} 10.639 / 2003$}

A educação nacional brasileira, por vários séculos, foi conduzida e tratada de forma homogênea sob o manto da chamada "democracia racial" ${ }^{3} \mathrm{de}$ povo mestiço e igual a todos os não negros, em que toda diversidade nacional fora encoberta, sendo que a única diferença percebida era a econômica. As diferenças de "raça", gênero e orientação sexual só passaram a ser discutidas de formas contundentes no final da década de 80 do século passado, a partir da rearticulação dos movimentos sociais, em sua maioria, de caráter identitários como, por exemplo, o movimento negro.

É importante ressaltar que o ensino universalista adotado no Brasil não leva em consideração a diversidade da constituição do povo brasileiro. Nesse interim, se faz necessária uma nova proposta educacional com um olhar que passa pela lógica da diversidade, na qual se constitui a nação brasileira. Observando que todo processo de ensino nacional, até as últimas décadas do século XX, foi pautado na hegemonia ocidental de dominação masculina, branca e heterossexual, o qual não levava em consideração a cultura e os

\footnotetext{
3 "Mito da democracia racial": A crença de que no Brasil não existem conflitos raciais é o resultado da difusão do conceito de democracia racial, principalmente a partir da segunda metade do século XX. O sociólogo Gilberto Freyre, que em 1933 publicou a obra "Casa Grande e Senzala", é considerado um dos principais difusores da ideia de que no Brasil, brancos e negros mantêm relações pacíficas e harmoniosas - embora nunca tenha adotado explicitamente este conceito, mas apenas usado uma expressão sinônima, "democracia étnica". As estatísticas são eloquentes quanto a isso, na medida em que compõem o retrato de um Brasil profundamente desigual, cuja linha de corte é justamente a cor da pele. Em nosso país, os negros têm menos oportunidades de estudar, seus salários são menores que os dos brancos e eles são as principais vitimas da violência.

Fonte: Revista: Pré-Univesp, $\mathrm{n}^{\circ} 56$ abril de 2016. Disponivel em:

<http://pre.univesp.br/democracia-racial\#.VxZ5mnOrIdU>. Acesso em: 18 abr. 2016.
} 
valores indígenas e africanos que, juntamente com a cultura europeia, contribuíram para a formação identitária brasileira.

Diante do panorama exposto, nota-se a presença de questões sérias e urgentes, frentes às quais a educação passa a ser sinônimo de desenvolvimento. Desse modo, institucionaliza-se no Brasil importantes leis como: a Constituição Federal de 1988 de caráter democrático e igualitário, e a Lei 10.639/03 que alterou a LDB/96 tornando obrigatória a reconstrução curricular, a fim de institucionalizar estudos afros nas escolas. Permitindo, assim, reconstruir a história do povo brasileiro a partir de uma nova historiografia que tem por objetivo reparar injustiças históricas cometidas anos a fios com o afro-brasileiro, mascarado na justificativa da democracia racial, como afirma Moya e Silvério.

É apenas com a aprovação da Lei 10.639 em 2003 que a LDB é alterada e passa a incorporar a diferença, ou seja, após quatro anos de aprovação da LDB é possivel se pensar em uma lei que parte do reconhecimento da diferença e de sua afirmação e valorização no cotidiano escolar. (MOYA; SILVÉRIO, 2010, p.58).

Ao analisar a implementação das leis citadas no parágrafo anterior, é importante notar que a educação básica no Brasil - enquanto um direito social de todos os cidadãos - é recente. Isso se dá considerando que a história educacional brasileira, durante centenas de anos, foi voltada para uma minoria branca e economicamente elitizada. Processo que somente foi alterado com a Constituição Federal de 1988 e pela Lei de Diretrizes e Bases da Educação Nacional 9.394/96, a partir desse marco conquistas de direitos educacionais para todos foram institucionalizados.

Todavia a existência das leis que amparam a educação no Brasil não é um sinônimo de eficácia, pois Luis, Silva e Pinheiro (2011) constataram em várias regiões da federação um considerável índice de analfabetismo. Assim expondo que o Estado não tem cumprido em sua totalidade com o que determina a Constituição Federal de 1988, de que é dever do mesmo a oferta obrigatória e gratuita do ensino fundamental, da educação infantil (para crianças de até quatro anos de idade) e da oferta de ensino noturno regular. 
Salientando que a educação básica consiste na Educação Infantil, Ensino Fundamental e Ensino Médio. Ensinos estes que devem ser oferecidos a todos brasileiros, através de um regime de colaboração entre a União, os estados, o Distrito Federal e os municipios.

Pensando as políticas educacionais no âmbito social, é necessário que as mesmas busquem a redução das desigualdades, promovendo a equidade e a justiça através de politicas permanentes que perpassem o término de cada governo, como: a Lei de Diretrizes e Bases da Educação Nacional (LDB), a Lei $n^{\circ}$ 10.639/2003, o Plano Nacional de Educação (PNE), entre outras.

Mesmo que haja contestação, é importante frisar que as politicas públicas educacionais são ações do Estado para fazer cumprir as leis, portanto direitos de todos os cidadãos brasileiros, e não uma ajuda de caráter paternalista, como alguns alegam, mas um direito conquistado através de lutas e reivindicações populares, as quais deram origem às suas institucionalizações. Sendo necessário integrar as temáticas étnico-raciais na área de Ciências Humanas, para que o currículo e o material didático utilizado nas escolas tragam uma abordagem positiva sobre a cultura afro-brasileira e africanidade, e que sejam implantadas políticas públicas de ação afirmativa, de direitos iguais entre os diferentes.

\section{Embates e conflitos na formulação do currículo}

Analisando que o histórico das questões curriculares funde-se com a própria história da educação, bem como com as relações sociais e políticas da humanidade, faz-se mister ponderar sobre as teorias do currículo que se edificam através de um jogo de poder, conflitos e embates para assim melhor compreender as politicas públicas educacionais.

De acordo com Silva (2011), as grandes categorias da teoria do currículo são as teorias tradicionais, teorias críticas e teorias pós-críticas; e são nestas diferentes teorias e nos mais diversos momentos que o currículo se define. Nesta perspectiva, a questão primordial para a teoria do currículo é a de, 
[...] saber qual conhecimento deve ser ensinado. De uma forma mais sintética a questão central é: o quê? Para responder a essa questão, as diferentes teorias podem recorrer a discussões sobre a natureza da aprendizagem ou sobre a natureza do conhecimento, da cultura e da sociedade. (SILVA, 2011, p. 14)

Considerando que o currículo tem o objetivo de moldar o indivíduo com determinado conhecimento para formar um cidadão ideal, seja para o mundo do trabalho, bem como para serem pessoas críticas e reflexivas, todas as teorias curriculares voltam-se para um ponto central sobre qual o conhecimento é considerado válido ou essencial para serem selecionados a fazerem parte do currículo.

Para compreender o contexto em que foi formulada e que está sendo implementada a Lei $\mathrm{N}^{\mathrm{0}}$ 10.639/03, é importante analisar as teorias póscríticas do currículo em suas vertentes pós-estruturalista, pós-modernista pós-colonialista e os estudos culturais, correntes teóricas estas que nortearam esta pesquisa de maneira mais próxima aos estudos culturais.

As vertentes pós-críticas reivindicam um currículo que inclua as diferentes culturas, as experiências de povos e grupos até então inferiorizados, mas não de maneira simplista e informativa, mas que traga reflexões e análises culturais.

As discussões e reflexões de temáticas relacionadas à diversidade cultural vêm, cada vez mais, ganhando visibilidade no cenário internacional e nacional. De forma especial a partir dos anos de 1980 os debates, seminários, congressos e produções acadêmicas têm se intensificado em todo mundo e denunciado as várias formas de discriminações, ao mesmo tempo em que buscam reconhecimento e valorização de suas particularidades, ações estas requeridas principalmente pelos movimentos sociais de caráter identitário.

As últimas décadas do século XX, situado por Hall (1997) na chamada pós-modernidade é identificado por este pesquisador como "revolução cultural”. Contexto esse que Candau e Moreira (2014) argumentam:

A cultura adquiriu uma importância sem precedentes no que se refere à estrutura e à organização da sociedade contemporânea, aos processos de desenvolvimento do meio ambiente e a distribuição de recursos materiais e humanos. Em termos 
epistemológicos, a sua cultura tem favorecido a emergência de novas visões, explanações e teorizações do mundo. (CANDAU; MOREIRA, 2014, p. 08).

As transformações culturais têm viabilizado a expansão dos meios de produção, a troca e difusão de cultura, com impacto global, atingindo e modificando o cotidiano das pessoas; ora reforçando tendências unificadoras, ora acentuando diferenças culturais, como esclarece Candau e Moreira (2014)

Embora seja possivel observar tendências à homogeneização que contribuem para diluir características particulares e locais, as conseqüências desse processo são contraditórias e incluem, ao mesmo tempo, o reforço de diferenças culturais e a criação de alternativas híbridas. A cultura transformou-se, assim, em um dos elementos mais dinâmicos e imprevisiveis das mudanças históricas na contemporaneidade. (CANDAU; MOREIRA, 2014, p. 08)

Estas questões, advindas das diferenças culturais, têm instigado os sistemas de ensino e o poder público a buscarem novas práticas educacionais e a questionarem o currículo nacional, que até então foi constituído pela hegemonia da cultura ocidental europeia.

Diante do reconhecimento das diferenças, a cada dia mais visivel e da centralidade da cultura nas discussões acadêmicas sobre a sociedade e a educação, Candau e Moreira (2014) acentuam a necessidade de enfrentar o desafio na organização do currículo que considera as diferenças culturais que superando o que alguns autores chamam de "daltonismo cultural", ou seja, a visão distorcida e insensivel dos educadores para a heterogeneidade que compõem as escolas brasileiras. Para desconstruir o chamado "daltonismo cultural" estes pesquisadores apresentam a perspectiva da educação intercultural. Sobre o "daltonismo cultural" se entende:

Expressão usada por Stephen Stoer e Luiza Cortesão (1999), para destacar a insensibilidade docente à heterogeneidade nas escolas, ao arco-íris de culturas que hoje marca toda e qualquer sala de aula em inúmeros países, entre os quais certamente se encontra o Brasil. Adotando essa perspectiva limitada, o (a) professor (a) termina por ver seus estudantes como idênticos, com interesses e necessidades similares. Deixa, então, de considerar a importância de organizar o currículo levando em conta essas diferenças. (CANDAU; MOREIRA, 2014, p. 12) 
Estes pesquisadores defendem o interculturalismo como capaz de promover a interação e a comunicação no ensino-aprendizagem, em uma dialógica democrática de respeito recíproco entre os diferentes atores e grupos sociais. Constituindo uma prática através da qual "[...] sejamos capazes de desenvolver currículos que incorporem referentes de diferentes universos culturais, coerentes com a perspectiva intercultural crítica". (CANDAU; MOREIRA, 2014, p. 35).

A concepção intercultural para Candau insere-se na corrente multicultural, a qual se classifica em três abordagens: “[...] o multiculturalismo assimilacionista, o multiculturalismo diferencialista ou monoculturalismo plural e o multiculturalismo interativo, também denominado interculturalidade" (CANDAU, 2014. p. 28). O multiculturalismo assimilacionista trabalha na perspectiva de que se vive os aspectos culturais de forma homogênia, não considerando os diferentes atores sociais. Já o multiculturalismo diferencialista propõe ações reconhecendo as diferenças e buscando espaços em que as diversas identidades culturais possam se expressar, todavia nesta abordagem há o risco de criar separações, ou seja, segregações enormes entre grupos sócio-culturais diferentes. E o multiculturalismo interativo ou interculturalidade que:

Trata-se de questionar as diferenças e desigualdades construídas ao longo da história entre diferentes grupos socioculturais, ético-raciais, de gênero, orientação sexual, entre outros. Parte-se da afirmação de que interculturalidade aponta à construção de sociedades que assumam as diferenças como constitutivas da democracia e sejam capazes de construir relações novas, verdadeiras, igualitárias entre os diferentes grupos socioculturais, o que supõe empoderar aqueles que foram historicamente inferiorizados. (CANDAU; MOREIRA, 2014. p. 28).

Assim, nota-se que Candau assume a perspectiva da interculturalidade crítica, como prática pedagógica na construção de um currículo que reconheça a dignidade, a importância e a diversidade de todos os sujeitos que compõe a sociedade se estão presentes nas nossas escolas. Um currículo que tem como base os estudos culturais e considera as questões culturais, enquanto um jogo 
de poder. E o conhecimento deve permitir concebê-los, "[...] como campos culturais, campos sujeitos a disputa e a interpretação, nos quais diferentes grupos tentaram estabelecer sua hegemonia". (SILVA, 2011, p.153)

Nesta concepção o currículo não deve ser hierarquização dos conhecimentos, mas uma conexão entre os mesmos, ou seja, a complementação dos conhecimentos formais adquiridos na escola e dos já existentes no cotidiano dos educandos.

É importante ressaltar que, com as teorias críticas e pós-críticas do currículo, não se pode mais olhar o mesmo com a inocência de antes, desconsiderando as relações de poder o qual o currículo se constitui. Nesta perspectiva,

[...] o currículo tem significados que vão muito além daqueles aos quais as teorias tradicionais nos confinaram. O currículo é lugar, espaço, território. O currículo é relação de poder. O currículo é trajetória, viagem, percurso. O currículo é autobiografia, nossa vida: curriculum vitae: no currículo se forja nossa identidade. O currículo é documento de identidade (SILVA, 2011, p. 150).

O currículo sempre traz muito mais do que ele se mostra, está sempre direcionando as relações sociais e escolares.

\section{Currículo de Ciências Humanas, Linguagens, Códigos e suas tecnologias no ensino médio do estado de SP e a inserção da Lei $n^{\circ} 10.639 / 2003$}

O currículo do Estado de São Paulo foi gestado a partir de 2008 para ser publicado em 2010, no governo do Geraldo Alckmin, tendo como secretário da educação Paulo Renato Souza. Segundo esse documento durante todo período de elaboração foram ouvidos os trabalhadores da área educacional para melhor adequar os conteúdos selecionados, o material didático a ser utilizado e a metodologia trabalhada. O documento pretende que todos os alunos em idade escolar possam ter um núcleo comum de aprendizagem em todo estado e definir as metas de conhecimento a serem alcançadas, além de avaliar o ensino aprendizagem com base nas competências e habilidades adquirida pelos estudantes. O currículo apresenta também material a ser 
utilizado pelo grupo gestor e professores, no sentido de capacitar e subsidiar esses profissionais para realizarem com autonomia a implementação desse documento.

Definir o objetivo curricular não consiste em tarefa fácil, porém necessária para compreender as relações sociais e política que envolvem o cotidiano escolar. Diante dessa dificuldade Coll (1996) define como objetivo principal do currículo explicitar com clareza tanto o projeto que serve de guia para as atividades educativas nas escolas, quanto as suas intenções, objetivos e planos de ações.

São vários os documentos educacionais nacionais que definem currículo, entre eles pode-se encontrar no artigo $5^{\circ}$ da lei 7.044 , de 18 de outubro de 1982:

Os currículos plenos de cada grau de ensino, [são] constituídos por matérias tratadas sob a forma de atividades, áreas de estudo e disciplinas, com as disposições necessárias ao seu relacionamento, ordenação e sequência, [e] serão estruturados pelos estabelecimentos de ensino. (BRASIL, 2009).

Esta definição para currículo pode ser observada também na Lei de Diretrizes e Bases da Educação Nacional (LDB) 9.394/96 que garante, em seu artigo 26, os princípios de descentralização e flexibilidade curricular:

Os currículos do ensino fundamental e médio devem ter uma base nacional comum, a ser complementada, em cada sistema de ensino e estabelecimento escolar por uma parte diversificada, exigida pelas características regionais e locais da sociedade, da cultura, da economia e da clientela. (BRASIL, 2009).

Nesta perspectiva, o currículo do Estado de São Paulo defende que este documento "define a escola como espaço de cultura e de articulação de competências e de conteúdos disciplinares" (SÃO PAULO, 2010, p.7). Completa ainda que o "Currículo é a expressão do que existe na cultura científica artística e humanista transposta para uma situação de aprendizagem e ensino". (SÃO PAULO, 2010, p.11). 
No Estado de São Paulo, o Currículo na área de Ciências Humanas centra seus objetivos nas competências e habilidades leitoras dos educandos com os principios:

a escola que aprende; currículo como espaço de cultura; competências como eixo de leitura e de escrita; a articulação das competências para aprender; e a contextualização no mundo do trabalho. (SÃO PAULO, 2010, p.10).

O currículo do Estado de São Paulo, no contexto de Ciências Humanas e suas Tecnologias,traz, além da definição e objetivos deste documento, a concepção do ensino na área de humanas. Apresenta também de forma específica o currículo de: História, Geografia, Filosofia e Sociologia. Ao final de cada currículo por área, há um quadro dos conteúdos dividido por bimestre de todas as séries/ano referente ao ensino fundamental e ensino médio. Os conteúdos direcionados ao ensino fundamental e médio do currículo de História trazem temas indicados pelas "Diretrizes Curriculares Nacionais para Educação das Relações Étnico-raciais e para o Ensino de História e Cultura Afro-Brasileira e Africana" (BRASIL, 2004). Sendo que esta pesquisa limita-se a analisar o currículo do ensino médio da área de humanas e as disciplinas de Arte e Língua Portuguesa na área de Linguagens, Códigos e suas tecnologias. Estudar estas disciplinas explica-se por serem ciências que buscam desvendar e compreender a acumulação cultural gerada por diferentes povos. Embora nas determinações da Lei $\mathrm{N}^{\circ} 10.639 / 03$, todas as disciplinas do currículo da educação básica deva trabalhar com temas que inclua História da África e dos africanos, bem como a luta dos negros e a cultura afro-brasileira, são as disciplinas de Arte, Língua Portuguesa e História que têm a incumbência de ministrar estes conteúdos de forma especial conforme os termos da lei 10.639/03, “[...] § 2o Os conteúdos referentes à História e à Cultura Afro-Brasileira serão ministrados no âmbito de todo o currículo escolar, em especial nas áreas de Educação Artística e de Literatura e História Brasileira”. (BRASIL, 2003).

As disciplinas de Sociologia, Geografia e Filosofia trazem em sua essência estudos culturais que contribuem para a formação de cidadãos críticos e reflexivos, conhecedores dos seus direitos e deveres. No currículo do 
Estado de São Paulo, nas disciplinas as quais se propõem pesquisar incluindo os cadernos do professor e dos alunos, material de apoio do currículo, podem identificar-se, importantes temáticas que abordam as questões culturais afrobrasileiras e formas recentes de luta das comunidades negra contra o racismo e em favor da igualdade de direitos entre os diferentes.

O currículo do Estado de São Paulo não adota para a área de humanas uma única corrente historiográfica, filosófica ou sociológica viabilizando assim que os professores transitem entre os temas com autonomia, podendo realizar um trabalho interdisciplinar.

A autonomia identificada no currículo do Estado de São Paulo para ensino médio e o material de apoio fornecido pelo governo: livros didáticos, paradidáticos, vídeos entre outros, permitem que professores com apoio do grupo gestor, possam desenvolver projetos com temáticas que trabalhem as questões étnico-raciais, a história de África e do afro-brasileiro.

Para melhor compreensão de como os temas referentes à África, cultura afro-brasileira e as relações étnico-raciais brasileiras articulam-se no currículo do Estado de São Paulo e no material de apoio, nas disciplinas de História, Geografia, Sociologia, Filosofia, Arte e Língua Portuguesa, apresentar-se-á de forma crítica e reflexiva os conteúdos do $1^{\circ}, 2^{\circ}$ e $3^{\circ}$ ano do ensino médio os quais são abordados no currículo e no caderno do professor/aluno.

O currículo de História é organizado por tema e no $1^{\circ}$ ano do ensino médio é estudado o Egito na mesma situação de aprendizagem que a Mesopotâmia; democracia e escravidão no mundo antigo e no mundo contemporâneo; e as características econômicas, políticas, culturais e religiosas das sociedades africanas da região subsaariana até o século $\mathrm{XV}$. Observando que no material de apoio (caderno do professor e do aluno) os temas estão expostos com os mesmos títulos apresentados no currículo.

No primeiro bimestre, os cadernos do professor e do aluno ao tratar do Egito trazem os conteúdos a serem trabalhado em uma mesma situação de aprendizagem que a Mesopotâmia, explorando questões como as primeiras civilizações que desenvolveram a escrita, o politeísmo enquanto religião e a 
formação política das primeiras cidades. Além disso, traz mapa de localização das duas civilizações mencionadas. O tema é apresentado sem fazer nenhuma articulação da história da África e a história dos afro-descendentes no Brasil. Logo, nota-se que não foi observado para este conteúdo determinações das "Diretrizes Curriculares Nacionais para a Educação das Relações ÉtnicoRaciais e para o Ensino de História e Cultura Afro-Brasileira e Africana" cujo documento traz em seu texto:

Em História da África, tratada em perspectiva positiva, não só de denúncia da miséria e discriminações que atingem o continente, nos tópicos pertinentes se fará articuladamente com a história dos afrodescendentes no Brasil e serão abordados temas relativos: - ao papel dos anciãos e dos griots como guardiões da memória histórica; - à história da ancestralidade e religiosidade africana; - aos núbios e aos egípcios, como civilizações que contribuíram decisivamente para o desenvolvimento da humanidade. (BRASIL, 2004, p. 21-22).

$\mathrm{Na}$ situação de aprendizagem "Democracia e escravidão no mundo antigo e no mundo contemporâneo" descrita para ser trabalhada no $2^{\circ}$ bimestre, o conteúdo trata das especificidades da escravidão na Grécia Antiga, sendo possivel, no entanto, identificar que a temática proposta realiza importante articulação com outras formas de escravidão na antiguidade e com a origem dos negros escravizados no Brasil. O currículo neste momento possibilita que o professor aborde as diferenças entre a escravidão na antiguidade e a escravidão na América Colonial.

O $3^{\circ}$ bimestre, o material não propõe conteúdos relacionados à África ou a cultura afro-brasileira. Já no $4^{\circ}$ bimestre, o tema "sociedades africanas da região subsaariana até o século XV" propicia estudar e compreender a África enquanto um continente único e diverso, com regiões e povos dotados de culturas próprias. Possibilitando um debate a fim de desmistificar o continente africano como lugar de povos primitivos e atrasados. Não obstante, apresenta a África Subsaariana com suas especificidades culturais, politica, econômica, social e religiosa, de forma positiva. O material de apoio traz mapas de África, em que é possível realizar localização dos países que fazem parte da África subsaariana, esquemas que facilitam o ensino- aprendizagem 
e também excertos interessantes dos estudiosos Priore, Mary Del e Venâncio, Renato Pinto sobre a África tradicional auxiliando o trabalho do professor e o entendimento dos alunos. Todavia, o tema "Democracia e escravidão no mundo antigo e no mundo contemporâneo" compõe penúltima situação de aprendizagem do $4^{\circ}$ bimestre, podendo ser comprometido pelo pouco tempo no final do ano letivo.

O segundo ano do ensino médio apresenta a África e a cultura afrobrasileira apenas nos $1^{\circ}$ e $4^{\circ}$ bimestres. Contudo, nos demais bimestres, por que, ao abordar os sistemas coloniais na América, não tocar em questões voltadas para a escravidão negra? Ao analisar os conteúdos do segundo $2^{\circ} \mathrm{e}$ $3^{\circ}$ bimestre, que não contemplam esta temática, é possivel se perguntar por que nestes momentos ao trabalhar sistemas coloniais na América, não integra conteúdos sobre a escravidão negra?

No $1^{\circ}$ bimestre em que se trabalha com o tema "Encontros entre europeus e as civilizações da África, da Ásia e da América”, não se dá muita ênfase ao encontro entre os europeus e os africanos, justificando esta ausência por não encontrar documentos textuais em edições brasileiras dos relatos descrevendo os primeiros contatos entre europeus e africanos. O material indica como referência para o ensino-aprendizagem desse conteúdo "A formação do Império Português (1415-1580)" de Janaina Amando e Luiz Carlos Figueiredo. São Paulo: Atual, 1999.

No $4^{\circ}$ bimestre o tema, "Abolição da escravatura e imigração europeia para o Brasil" aborda importantes estudos relacionados à libertação dos escravos, pela princesa Izabel em 1888, e todo contexto político social deste período, com as leis que antecederam a lei Áurea. Ademais, o material de apoio traz uma carta de um ex-escravo publicada em 19/05/1888, ou seja, logo após a libertação, documento muito interessante para que os estudantes compreendam o contexto em que ocorre o fato.

Enfim, ao analisar o currículo e o material de apoio foi possivel observar que no $4^{\circ}$ bimestre, quando o estudo refere-se à Guerra Civil, também conhecida como Guerra de Secessão nos Estados Unidos, faz-se mister a discussão sobre as diferentes formas de "racismo", fazendo um paralelo entre 
as formas de racismo existente nos Estados Unidos e no Brasil. Para tanto, é necessário considerar a construção histórica de cada um desses países, o que permitiria ótima reflexão sobre a influência do passado colonial nas relações étnico-raciais nas sociedades pós-moderna.

Por fim, o $3^{\circ}$ ano do ensino médio inicia-se com o tema: "Imperialismos e Gobineau e o racismo". A fim de promover o desenvolvimento do conteúdo relacionado ao neocolonialismo ou imperialismo europeu sobre África e Ásia no final do século XIX, o material de apoio traz o texto do francês Conde de Gobineau, “L' émigrationauBrésil, 1873”. Documento que serve de base para a discussão sobre a origem das práticas racistas e também o entendimento do pensar europeu em relação ao negro africano e o afro-brasileiro no final do século XIX e primeira metade do século XX. Proposto nesta mesma unidade de aprendizagem, o poema "Cena de Ódio" de José de Almada possibilita observar que havia também uma literatura contraria ao pensar europeu de superioridade e inferioridade de "raças", pois o poema faz sérias criticas à chamada superioridade europeia”.

Esta temática exposta no $3^{\circ}$ ano do ensino médio constitui o único momento em que se trabalha conteúdo referenciado pelas "Diretrizes Curriculares Nacionais para a Educação das Relações Étnico-Raciais e para o Ensino de História e Cultura Afro-Brasileira e Africana" (BRASIL, 2004) No entanto no $4^{\circ}$ bimestre ao propor estudos sobre o Brasil na década de 80 do século passado, período de redemocratização brasileira pós-ditadura militar e organizações de grupos étnicos minoritários, o movimento negro que se organiza em busca de políticas públicas de reparações, reconhecimento e valorização de sua história, cultura e identidade. Contudo, observa-se que nesta disciplina não ocorre, nesse momento, indicação para estudar sobre a importância do movimento negro. Questão que será explorada na disciplina de Sociologia ao tratar dos movimentos sociais contemporâneos. Logo, fica evidente a importância do trabalho interdisciplinar entre as várias áreas do conhecimento para se implementar a Lei $n^{\circ} 10.639 / 03$ no lócus escolar, uma vez que conteúdo mencionado é essencial para que o estudante possa compreender a luta das comunidades negras por direitos iguais entre os 
diferentes e formas de manifestações que identifica a cultura negra, seja, através da música, da dança, do grafite ou do próprio estilo de se vestir, de usar o cabelo blackpower etc. Interessante ressaltar que o hip-hop leva também os jovens à reflexão e à discussão sobre questões raciais, sociais e políticas.

O ensinar e aprender História, que vem ocorrendo no Brasil, no pós Ditadura Militar, revela um contexto de luta e resistência à política educacional tradicional em que estudar História consistia em repetir e reproduzir conhecimentos, produzidos em outros espaços, sem nenhuma preocupação com a cultura escolar. E neste contexto de reafirmação das práticas educativas, de transformações nas políticas sociais, atreladas ao movimento acadêmico multicultural crítico, foi institucionalizando a Lei Federal 11.645 de 10 de março de 2008. Lei esta que alterou a Lei 9.394, de 20 de dezembro de 1996, modificada pela Lei 10.639, de 09 de janeiro de 2003, estabelecendo as diretrizes e bases da educação nacional, para incluir, no currículo oficial da rede de ensino, a obrigatoriedade da temática "História e Cultura Afro-Brasileira e Indígena", com alterações no artigo 26-A. No entanto ao analisar o currículo de História da rede pública do Estado de São Paulo é perceptível a ausência de temas que tratam de África entre os séculos XV e XIX há um silêncio no currículo em relação esse período. O que remete às indagações: como viviam os vários povos africanos neste período? Porque não se explora estudos sobre a África tradicional no currículo de História? Entre o não explícito no currículo de História, também se pode constatar a ausência do cotidiano do negro pós-libertação, em 13 de maio de 1888, e a sua luta para se inserir em uma sociedade de classe, assim como a vida em família do escravo não são mencionadas. Outro fato que pode ser pensado de forma crítica são os vários momentos em que o currículo trata de um tema, sem esclarecer o significado e importância da nomenclatura, como por exemplo, "cidadania". No currículo, alguns conteúdos são colocados em uma concepção naturalizada, como um conhecimento universal, que todos possuíssem. Estas lacunas no currículo de História precisam ser identificadas e melhor conduzidas, para que em um país como o Brasil que segundo o IBGE (2010) 
$50 \%$ da população se autodeclara negra ou parda, todos tenham a oportunidade de conhecer a História de África, sua cultura e as contribuições dos povos africanos para formação da identidade nacional.

A Sociologia, como Ciência Humana no currículo do estado de São Paulo, tem a capacidade de produzir conhecimentos específicos, ao passo que tem poder de mediar e instigar a participação consciente, racional e bem informada dos estudantes nas questões públicas, levando-os a serem agentes transformadores do meio social em que vivem.

Nessa perspectiva, o currículo de Sociologia do estado de São Paulo apresenta em seus conteúdos, mais que apenas referências sociológicas, mas as Ciências Sociais em seu conjunto, incorporando aspectos antropológicos e da Ciência Politica. Considerando o conjunto, o currículo de Sociologia “[...] entende-se que o objetivo geral da disciplina é levar o aluno a compreender quem ele é enquanto membro da sociedade brasileira". (SÃO PAULO, 2010, p.133).

Sendo assim, o material de apoio, caderno do professor e do aluno, da disciplina de Sociologia aborda as questões ou problemas sociais através de textos atuais utilizando como fontes jornais, revistas e livros; além de gêneros específicos como gráficos, tabelas e imagens. Referenciais que instigam o estudante a se envolver com a temática proposta. Embora a disciplina de Sociologia não seja referenciada como obrigatória para a implementação da Lei $\mathrm{n}^{\mathrm{o}} 10.639 / 03$, é nesta área do conhecimento que o currículo do estado de São Paulo aborda temas contemporâneos relacionados às questões das diferenças, de descriminação, das etnias e as lutas sociais do final do século XX e início do XXI.

Neste contexto, no $1^{\circ}$ ano do ensino médio o tema proposto é a desigualdade racial, iniciando os estudos conceituando raça, etnia, racismo, estereótipos, preconceito etc. Esta situação de aprendizagem apresenta maior ênfase na questão do racismo existente no Brasil, mesmo que de forma velada. Os gráficos demonstram, através da estatística, a situação de vulnerabilidade maior entre os negros na questão do analfabetismo, do desemprego do salário e mesmo de gênero. No $2^{\circ}$ ano do ensino médio, os conteúdos com temas 
relacionados à educação étnico-raciais apresentam um gráfico com o índice de homicídio entre brancos e negros de 15 e 24 anos, constatando que em todas as regiões brasileiras o índice de mortalidade do jovem negro é muito maior que do branco sendo de 30,2 de brancos e 70,6 de negros para cada 100 mil (v. 2, p.52). Em outra situação de aprendizagem que trata sobre a diversidade na formação identitária brasileira, o material de apoio traz textos sobre os imigrantes, as dificuldades de estar em terras estranhas e o processo de assimilação de cultura, porém a imagem que aparece no contexto com o título "Grupo de adolescente de diversas etnias", o negro não se faz representado, mesmo com os dados do (IBGE, 2010) de que 50\% da população brasileira auto se declara negra ou parda.

Essa observação indica que mesmo com a Lei $n^{\circ} 10.639 / 03$, que completa 14 anos em 2017, o material didático precisa continuar sendo revisto e reformulado, para que o negro possa se ver representado em todos os segmentos: politicos, sociais, econômicos e culturais.

O movimento Negro abordado no $3^{\circ}$ ano do ensino médio está contextualizado em três fases distintas: movimentos abolicionistas e de libertação, movimentos de integração na sociedade de classe e movimentos de perspectiva socialista. Esta situação de aprendizagem apresenta também importantes personagens negras que contribuíram de forma positiva para a construção da nação brasileira, entre eles, André Rebouças, José do Patrocínio e Abdias Nascimento. Conteúdos estes determinados pelas "Diretrizes Curriculares Nacionais para Educação das Relações Étnico-raciais e para o Ensino de História e Cultura Afro-Brasileira e Africana" (BRASIL, 2004) nos termos:

O ensino de História e de Cultura Afro-Brasileira se fará por diferentes meios, inclusive, a realização de projetos de diferentes naturezas, no decorrer do ano letivo, com vistas à divulgação e estudo da participação dos africanos e de seus descendentes em episódios da história do Brasil, na construção econômica, social e cultural da nação, destacando-se a atuação de negros em diferentes áreas do conhecimento, de atuação profissional, de criação tecnológica e artística, de luta social. (BRASIL, 2004, p. 22). 
Assim como das demais áreas do conhecimento, o currículo de Geografia do estado de São Paulo propõe o ensino por competências, apresentando entre seus conteúdos estruturadores, temáticas sobre África no $3^{\circ}$ ano do ensino médio. Esta série, ao estudar a "A questão étnico-cultural", aborda os conflitos separatistas após a Guerra Fria (1947-1991) com mapas das regiões de guerra civil em África. No $3^{\circ}$ bimestre o conteúdo é todo dedicado à África no contexto global, explorando as questões geográficas que constitui o continente, e as transformações que vem ocorrendo na sociedade.

Quanto aos conhecimentos filosóficos, reconhecidos pela Lei de Diretrizes e Bases da Educação Nacional (LDBEN) de 1996, passando assim a fazer parte da grade curricular do ensino médio, têm como objetivo formar cidadãos críticos, reflexivos e éticos. Com este propósito, entre os conteúdos da disciplina de Filosofia foi identificado no tema, "Mito e Cultura" e na análise da "Declaração Universal dos Direitos Humanos" de 1948, a possibilidade de despertar no estudante compromissos de cidadania e respeito às diferenças. Estes temas estudados no $1^{\circ}$ ano do ensino médio são base para, no $2^{\circ}$ ano, os estudantes reconhecerem e questionarem as práticas racistas existentes no Brasil através do conteúdo "Filosofia e Racismo", proposto para esta série.

A Arte está inserida na área de Linguagens, Códigos e suas tecnologias. Sendo assim, ela se articula nos diferentes saberes da arte e da cultura, transitando entre linguagens artísticas, momentos de criação, materialidade, mediação cultural, patrimônio cultural e conhecimentos estéticos e culturais, o que permite à disciplina desenvolver projetos relacionados à cultura africana e afro-brasileira.

A Arte, assim como a Filosofia, tornou-se componente curricular a partir de 1996, com a (LDBEN), pois até então os saberes da Arte eram considerados atividades. O currículo de Arte ao abordar os estudos das artes visuais, da música, da dança e do teatro viabiliza o trabalho do professor nas várias áreas de atuação. Com o tema Patrimônio Cultural realiza-se o processo de criação, mediação e herança culturais. Assim, os estudos sobre cultura africana e afrobrasileira se fazem presentes, possibilitando trabalhar com carnaval, tambor de crioula, jongo, roda de samba, frevo, forró, dança contemporânea e dança 
popular. Ademais, nas artes visuais há a proposta de explorar o grafite, que alguns preferem denominar a partir de sua etimologia graffiti, muito presente nas cidades e praticado por jovens. Outro recurso muito utilizado é a música; o material de apoio traz letras de música de vários ritmos inclusive os de origem afro. Muito interessante é que esta disciplina apresenta também proposta de intervenção, em que professor e estudantes têm seus momentos de produção. O caderno do professor e do aluno propõe projetos poéticos cujo trabalho debruça-se sobre personagens negros que contribuíram para com a construção da nação brasileira e indica a realização de um festival. Momento propício para descobrir talentos e aproximar toda comunidade escolar. Não obstante, a proposta de trabalho analisada na disciplina de Arte é para todas as séries do ensino médio, porém com abordagens diferentes.

O currículo de Língua Portuguesa do Estado de São Paulo, para ensino médio, organiza os conteúdos em quatro campos de estudo: da linguagem e sociedade, leitura e expressão escrita, funcionamento da linguagem e produção e compreensão oral. Estes eixos permitem através das sequências didáticas do caderno do professor em consonância com o caderno do aluno, que o professor (a) desenvolva diferentes atividades incluindo as determinações da Lei $n^{\circ}$ 10.639/03, ou seja, os estudos da literatura africana e dos africanos, além da literatura afro-brasileira engajada possibilitando refletir sobre a luta dos negros escravizados no Brasil, o que leva os estudantes a compreensão de questões sobre o racismo que, embora de forma velada, fazse presente na sociedade brasileira e a desigualdade de oportunidades entre negros e não negros no presente.

Entre as várias situações de aprendizagens que abordam esses temas, "Lusofonia- sim, nós falamos português", o material de apoio traz textos de escritores como Machado de Assis e do moçambicano Mia Couto, também trabalha com mapas do Continente Africano em especial de países de língua portuguesa, permitindo que os estudantes conheçam aspectos diferentes de África, incluindo nestes conhecimentos notícias de jornais moçambicanos. Ao propor o tema "O presente do Passado hoje" estuda-se a produção do açúcar no Brasil colônia, isto através de poesias de denuncia escrita por Castro Alves 
e da observação e análise do cotidiano colonial com as pinturas do francês Jean-Baptiste Debret4 (1768-1848). Este conteúdo consiste em grande oportunidade para que o professor (a) de Língua Portuguesa possa realizar discussões e reflexões como: quais as relações sociais entre os senhores de engenho e os escravizados? Como era a escravidão no século XIX? Qual o contexto em que terminou a escravidão oficial no Brasil? Quais influências o período de escravidão oficial trouxe para a cultura brasileira? Quais as consequências históricas, sociais e econômicas que os mais de trezentos anos de escravidão ocasionam na sociedade brasileira hoje?

Interessante ainda é abordagem do tema "O presente faz poesia" com estudos da literatura angolana que surge no século $\mathrm{XX}$ e se firma crescentemente no cenário internacional. Nesta perspectiva, a proposta de trabalho analisa textos da poetisa angolana Paula Tavares. Ela representa não apenas a poesia de um país africano, mas a voz feminina, outra realidade bem diferente daquela vivida no século XIX.

Ao propor na disciplina de Língua Portuguesa situações de aprendizagens com referenciais da literatura africana e afro-brasileira, o material traz também textos atuais dos meios de comunicação, principalmente da folha de São Paulo, abordando temas polêmicos como o racismo, a discriminação e políticas de ações afirmativas, que irão corroborar na formação consciente dos estudantes em relação a questões étnico-raciais existente no Brasil.

\section{Considerações Finais}

As fontes pesquisadas nos esclarecem que o tripé (professor, aluno e currículo) forma um conjunto que se em sintonia influenciam-se mutuamente, determinando as formas de relações e ações pedagógicas em sala de aula.

\footnotetext{
${ }^{4}$ Jean-Baptiste Debret foi um pintor francês de grande importância para a história da arte no Brasil,viveu durante 15 anos no Brasil e desenvolveu uma intensa relação pessoal e emocional com o território brasileiro. Seu trabalho é considerado de grande importância para o Brasil na medida em que se dedicou a retratar o cotidiano e a sociedade do século XIX, especialmente no Rio de Janeiro. Disponivel em: <http://www.infoescola.com/biografias/jean-baptiste-debret/>. Acesso em: 25 set. 15.
} 
Nesta perspectiva, o currículo do estado de São Paulo, que é referenciado por competências é também espaço de cultura que possibilita professores e estudantes explorarem temas determinados nas "Diretrizes Curriculares Nacionais para Educação das Relações Étnico-raciais e para o Ensino de História e Cultura Afro-Brasileira e Africana", (BRASIL, 2004) e se apropriarem de conhecimentos sobre: África, escravidão miscigenação, mestiçagem e políticas públicas voltadas para práticas educativas de combate ao racismo, ao preconceito e a discriminação. Sendo assim, o currículo do Estado de São Paulo, em todas as áreas do conhecimento, tem como principal alvo as competências, esclarecendo que "um currículo que promove competências tem o compromisso de articular as disciplinas e as atividades escolares com aquilo que se espera que os alunos aprendam ao longo dos anos" (SÃO PAULO, 2010, p.14). Contudo, para que os conteúdos do currículo se efetivem é necessário, ao professor, disposição e segurança, para realizar um trabalho interdisciplinar que aborde as determinações da Lei $\mathrm{N}^{\circ} 10.639 / 03$, o que na prática, nem sempre ocorre. Estes saberes por competências verificados no currículo são verificados através do SARESP (Sistema de Avaliação do Estado de São Paulo). No entanto, este Estado é muito amplo e diverso, necessitando que sejam observadas as particularidades de cada município em relação à base comum proposta para todas as disciplinas.

No universo complexo de implementação do currículo de se fazer cumprir as determinações da Lei $\mathrm{N}^{\circ} 10.639 / 03$ e do trabalho dos professores, principais protagonistas na efetivação de uma educação voltada para as relações étnico-raciais, vai se costurando no cotidiano escolar experiências positivas e desvelando fatores dificultadores destas ações.

\section{Referências Bibliográficas}

ABREU, Martha; MATTOS, Hebe. Em torno das "Diretrizes Curriculares Nacionais para Educação das Relações Étnico-raciais e para o Ensino de História e Cultura Afro-Brasileira e Africana": uma conversa com historiadores. Estudos Históricos, Rio de Janeiro, v. 21, n. 41, p. 5-20, jan./jun. 2008.

BORGES, Marley de Fátima Morais. O Ensino de história, cultura africana e afro-brasileira na perspectiva da lei $n^{\circ}$ 10.639/03: análise de politicas 
públicas na EE. Prof. Hélio Palermo, cidade de Franca SP. Dissertação (Mestrado em Planejamento e Análise de Politicas Públicas) - Universidade Estadual Paulista, Franca, 2016.

BRASIL. Lei $\mathrm{n}^{\circ} 10.639,09$ de janeiro de 2003. Inclui a obrigatoriedade da temática "História e Cultura Afro-Brasileira" no currículo oficial da rede de ensino. Diário Oficial da União. Brasília, DF, 10 jan. 2003, seção 1, p. 1.

- Ministério da Educação. Secretaria Especial de Políticas da promoção da Igualdade Social. Diretrizes curriculares nacionais para a educação das relações étnico-raciais e para o ensino de história e cultura afro-brasileira e africana. Brasília, DF: Ministério da Educação, 2004.

. Lei $\mathrm{n}^{\circ} 9.394$ de 20 de novembro de 1996. Lei de diretrizes e bases da educação nacional. Disponivel em:

<http://www.planalto.gov.br/ccivil_03/LEIS/19394.htm.> Acesso em: 10 jun. 2013.

CALADO, Silvia dos Santos; FERREIRA, Silvia, Cristina dos Reis. Análise de documentos: método de recolha e análise de dados. Metodologia da investigação I. DEFCUL, 2004/2005.

CANDAU, Vera Maria. Educação intelectual: entre afirmações e desafios. In: MOREIRA, Antônio Flávio; CANDAU, Vera Maria (Org.). Currículos, disciplinas escolares e culturas. Petrópolis, RJ: Vozes, 2014.

COLL, César. Psicologia e currículo: uma elaboração psicopedagógica à elaboração do currículo escolar. São Paulo, SP: Ática, 1996.

DRAIBE, Sonia Miriam. Avaliação de implementação: esboço de uma metodologia de trabalho em políticas públicas. In: BARREIRA, Maria Cecília Roxo Nobre e; CARVALHO Maria do Carmo Brant de (Org.). Tendências e perspectivas na avaliação de politicas e programas sociais. São Paulo, SP: IEE/PUC-SP, 2001.

GOMES, Nilma Lino. As práticas pedagógicas com as relações étnico-raciais nas escolas públicas: desafios e perspectivas. In: Práticas pedagógicas de trabalho com relações étnico-raciais na escola na perspectiva da lei $n^{\circ}$ 10.639/03. Brasília, DF: MEC; UNESCO, 2012.

HALL, Stuart. A identidade cultural na pós-modernidade. Rio de Janeiro, RJ: Ed. Lamparina, 2014.

"A centralidade da cultura - Notas sobre as revoluções de nosso tempo". Educação \& Realidade, v. 22, p. 15-46, 1997. 
LUIZ, Maria Cecília; SILVA, Ana Lúcia Calbaiser da; PINHEIRO, Edinéia Virgínia. Políticas Públicas Pós 1988: uma leitura das políticas educacionais recentemente implementadas no Brasil. São Carlos, SP: UAB-UFSCar, 2011.

MUNANGA, Kabengele; GOMES, Nilma Lino. O Brasil, o que é afinal? In: . Para entender o negro no Brasil de hoje: histórias, realidades, problemas e caminhos. São Paulo, SP: Global, 2004.

OLIVA, Anderson, Ribeiro. Lições sobre A África-Diálogos entre as representações dos africanos no imaginário Ocidental e o ensino da história da África no Mundo Atlântico (1990-2005). Tese (doutorado em História) Universidade de Brasília, Brasília, DF, 2007.

PEDRA, José, Alberto. Currículo e conhecimento: níveis de seleção de conteúdo. Em Alberto, Brasília, n. 58, p. 30-37, 1993.

ROCHA, Luiz Carlos Paixão. Politicas Afirmativas e Educação: a lei 10.639/03 no contexto das politicas educacionais no Brasil contemporâneo. Dissertação (Mestrado em educação) - Universidade Federal do Paraná, Curitiba, 2006.

SANSONE, Lívio. Negritude sem etnicidade. Salvador/Rio de Janeiro: EDUFBA, 2004.

SÃO PAULO (Estado) Secretaria da Educação. Currículo do Estado de São Paulo. Currículo do Estado de São Paulo: ciências humanas e suas tecnologias. São Paulo, SP: SEE, 2010.

. Secretaria da Educação. Currículo do Estado de São Paulo: Linguagens, Códigos e suas tecnologias. Coordenação Geral: Ghisleine Trigo Silveira; coordenação da área, Alice Vieira. São Paulo, SP: SEE, 2010.

. Secretaria da Educação. Planejamento Escolar. Departamento de desenvolvimento curricular e de gestão da educação básica: temas transversais. São Paulo, SP: SEE, 2012.

SILVA, Tadeu da Silva. Documentos de identidade: uma introdução às teorias do currículo. São Paulo, SP: Ed. Autêntica, 2011.

. Identidades terminais: as transformações na politica da pedagogia e na pedagogia da política. Petrópolis, RJ: Vozes, 1996.

SILVÉRIO, Valter Roberto; MOYA, Thais Santos. Educação, diferença e desenvolvimento nacional. São Carlos, SP: UAB-UFSCar, 2010.

Recebido: 16 de agosto de 2017

Aceito: 10 de setembro de 2017

Publicado: 19 de setembro de 2017 